\title{
Chemical Characterization of the Essential Oil from Aerial Parts of Astragalus Maximus from Northwest of Iran
}

Javad Ghasemian-Yadegari ${ }^{1}$, Hossein Nazemiyeh ${ }^{1}$, Solmaz Asnaashari ${ }^{2}$, Fatemeh Fathiazad ${ }^{1 *}$

1. Department of Pharmacognosy, Faculty of Pharmacy, Tabriz University of Medical Sciences

2. Drug Applied Research Center, Tabriz University of Medical Sciences, Tabriz, Iran

\begin{abstract}
Purpose: The aim of the present study was to determine the chemical composition of essential oil of the aerial parts of Astragalus Maximus. Methods: The essential oil from the areal parts of Astragalus Maximus was isolated by hydrodistillation method and the composition of the volatiles was analyzed by gas chromatography (GC) method combined with flameionization detector (FID) and mass spectrometry (MS). Results and discussion: A total of 17 components accounting for $90.35 \%$ were identified using similarity searches between the mass spectra databases. The major components were identified as, Myristcin (29.4\%), Benzaldehyde,3-methyl (15.3\%), 1-Tridecanol (10.9\%), Acetophenone (10.7\%), 2Pentadecanone, 6,10,14-trimethyl (7.9\%) and Phytol (2.3\%). All of the identified compounds are Nonterpenoids and Myristcin with $29.4 \%$ was found the most abundant component of the essential oil of the areal parts of Astragalus Maximus. Conclusion: In general, results of the present investigation revealed that essential oil of Astragalus Maximus contains higher quantities of Non-terpenoid compounds.
\end{abstract}

Keywords: Astragalus Maximus; Essential oils; Gas chromatography

\section{Introduction}

Plants and herbal medicines usually display pharmacological properties and have been used for thousands of years for the treatments of different diseases. However, herbal medicines are very complex and contain a large number of chemical components. Furthermore, chemical species are commonly changed due to the variations of the growth environments and pretreating processes. Therefore, qualitative and quantitative analysis of chemical

components in plants is very challenging and important issue (1-3). Essential oils are highly concentrated natural oils extracted from plants, flowers, roots, wood, bark, or seeds; essential oils have been used for centuries in Iran and all over the world thanks to their definite pharmacological activities and low toxicity. They are widely used for different applications such as cosmetic including soaps, perfumes,

\section{Corresponding author:}

Fatemeh Fathiazad

Department of Pharmacognosy, Faculty of Pharmacy, Tabriz University of Medical Sciences, Daneshgah Ave. P.O.Box 51664-14776, Tabriz, Iran

Tel: +98 411 3372253. E-mail: Fathiazad@tbzmed.ac.ir

Receive date: 2015-04-01| Accept date: 2015-04-28| Publish date: 2015-05-03

DOI: 10.7575/aiac.abcmed.15.03.03.06

\section{A. I}


aromatherapy, skin care products and medicinal purposes (4-6).

The genus of Astragalus (Papilionaceae) is a member of the Fabaceae or Leguminosae family which includes more than 2000 species. It is widely distributed over the temperate regions of the world, mainly Europe, Asia and North America. The genus Astragalus contains about 800 species of perennial and annual plants most of which are endemic to Iran (79).The pharmacological effects of Astragalus spp. are very different including immunestimulant effects, anti-bacterial and antiviral properties, the ability to promote nucleic acid synthesis in the liver, hepatoprotective effects, anti-inflammatory activity, cardiovasculartonic effects such as hypotensive and vasodilatory action, as well as tonic, diuretic and anticancer properties. Additionally, gum tragacanth, which is a versatile food additive and used as pharmaceutical emulsifier, is a valuable and important derived product from Astragalus spp (9-16).

Chromatography is an important and a widely used separation technique of a complex mixture. Essential oils are mainly analyzed by gas chromatography (GC) combined with usually either flameionization detector (FID) or mass spectrometry (MS) $(17,18)$.

A literature review showed that there are a few reports about the phytochemical work performed on Astragalus Maximus and to the best of our knowledge, there is no previous report dealing with any investigation of the volatiles of this species in the literature. The main purpose of this investigation was to perform compositional analysis of the volatiles isolated by hydrodistillation technique using gas chromatography (GC) method combined with flameionization detector and mass spectrometry.

\section{Material and methods}

\section{Plant material}

The aerial parts of Astragalus Maximus were collected during flowering stage in June 2011 from Arasbaran (East Azarbayjan province, northwest of Iran) and subsequently authenticated by authors. Voucher specimens have been deposited at the herbarium of the Department of Pharmacognosy, Faculty of Pharmacy, Tabriz University of Medical Sciences, Tabriz, Iran.

\section{Essential oil isolation}

Essential oil was obtained from air-dried plant material by hydrodistillation using a Clevenger-type apparatus. Distillation was continued for 2 hours and xylene was used as the absorbing medium. Distillation yield was very low. The oily layer obtained was manually separated using a pasture pipette and then dried over anhydrous magnesium sulphate to remove traces of water and stored in sealed glass bottles, covered with an aluminum foil, at $4{ }^{\circ} \mathrm{C}$ until analysis (19).

Gas chromatography-Mass spectrometry (GCMS) analysis

The essential oils analysis was performed using a Shimadzu, QP 5050A gas chromatograph equipped with a FID detector and employing a DB-1 (methyl phenyl sylonane) capillary column $(60 \mathrm{~m} \times 0.25 \mathrm{~mm}$ i.d., $0.25 \mu \mathrm{m}$ film thickness).

For GC-MS detection, an electron ionization system, with ionization energy of $70 \mathrm{eV}$ was employed. Helium was the carrier gas, at a flow rate of $1.3 \mathrm{ml} / \mathrm{min}$ with linear velocity: 29.6 $\mathrm{cm} / \mathrm{s}$ and split injection with split ratio of 1:29. The GC conditions were set as the follows: column temperature, $2 \mathrm{~min}$ in $60^{\circ} \mathrm{C}, 50-260^{\circ} \mathrm{C}$ at $3^{\circ} \mathrm{C} / \mathrm{min}$; injector temperature, $240{ }^{\circ} \mathrm{C}$, and 1 $\mu \mathrm{L}$ of volume injection of the essential oil. Finally, the MS operating parameters were as follows: 
ionization potential, $70 \mathrm{eV}$; ion source temperature; $270{ }^{\circ} \mathrm{C}$; quadrupole $100{ }^{\circ} \mathrm{C}$, solvent delay $2 \mathrm{~min}$, scan speed $2000 \mathrm{amu} / \mathrm{s}$, scan range $30-600$ amu and EV voltage 3000 volts.

$\mathrm{RT}^{*} \quad$ Compounds

No.

\begin{tabular}{|c|c|c|c|}
\hline 1 & 16.216 & Benzaldehyde & 0.72 \\
\hline 2 & 20.411 & Benzeneacetaldehyde & 1.1 \\
\hline 3 & 21.815 & Acetophenone & 10.7 \\
\hline 4 & 22.031 & Benzaldehyde, 3-methyl- & 15.73 \\
\hline 5 & 22.708 & M-Tolualdehyde & 2.79 \\
\hline 6 & 24.357 & Benzaldehyde, 2-methyl- & 2.01 \\
\hline 7 & 24.619 & Linalool & 1.6 \\
\hline 8 & 29.37 & 3-Cyclohexene-1-methanol & 0.32 \\
\hline 9 & 40.245 & Dodecanal & 0.33 \\
\hline 10 & 42.134 & 5,9-Undecadien-2-one, 6,10-dimethyl & 0.74 \\
\hline 11 & 43.457 & Tridecanol & 10.95 \\
\hline 12 & 43.78 & $\begin{array}{l}\text { 3-Buten-2-one, 4-(2,6,6-trimethyl-1-cyclohexen- } \\
\text { 1-yl)-, (E)- }\end{array}$ & 1.03 \\
\hline 13 & 44.899 & Myristcin & 29.41 \\
\hline 14 & 53.652 & Hexadecanal & 2.19 \\
\hline 15 & 58.909 & 2-Pentadecanone, 6,10,14-trimethyl & 7.85 \\
\hline 16 & 62.908 & Hexadecanoic acid & 0.56 \\
\hline 17 & 68.462 & Phytol & 2.32 \\
\hline Total & & & 90.35 \\
\hline
\end{tabular}

Table 1: Essential oil composition of aerial parts of Astragalus Maximus

${ }^{*} \mathrm{RI}$ is the Retention Index relative to $\mathrm{C} 8-\mathrm{C} 24 \mathrm{n}$-alkanes on the DB-1 column

Identification of the compounds

The components were identified based on the comparison of their relative retention times and mass spectra with those of standards, National Institute of Standards and Technology (Nist) 21 and 107 as well as Wiley 229 library data of the GC-MS system and literature data
(20). Quantitative data were obtained electronically from FID area percent data.

\section{Results and discussion}

The total chromatogram of the essential oil extracted from the aerial parts of Astragalus Maximus is displayed in Figure 1. 


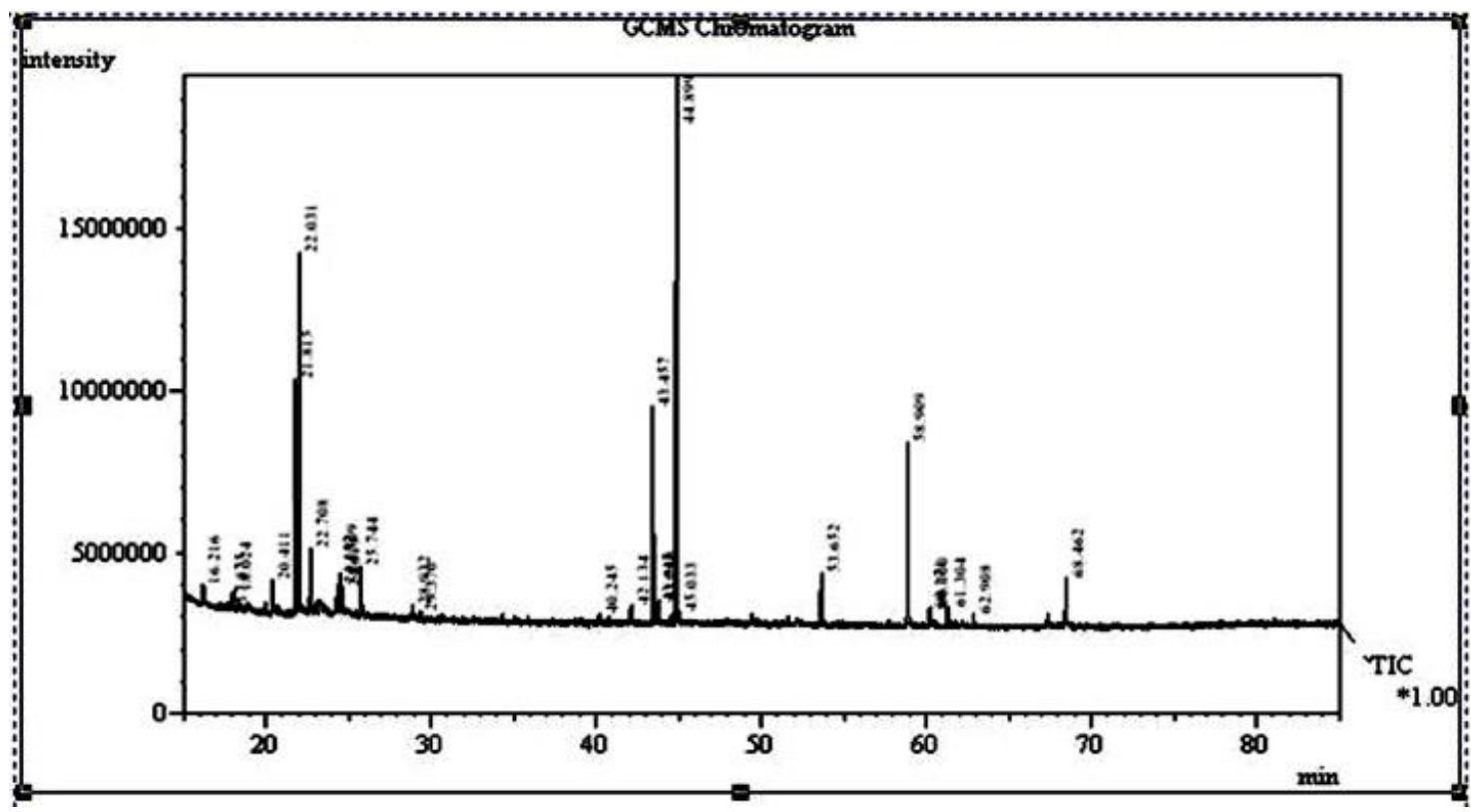

Figure 1: Chromatogram of essential oil composition of Astragalus Maximus

The essential oil of the aerial parts of the were recognized. All of the identified Astragalus Maximus, obtained by components were arranged in order of their hydrodistillation method, was analyzed by GC- retention time in the DB1 column and their MS technique and 17 different components fraction were shown in Table 1.

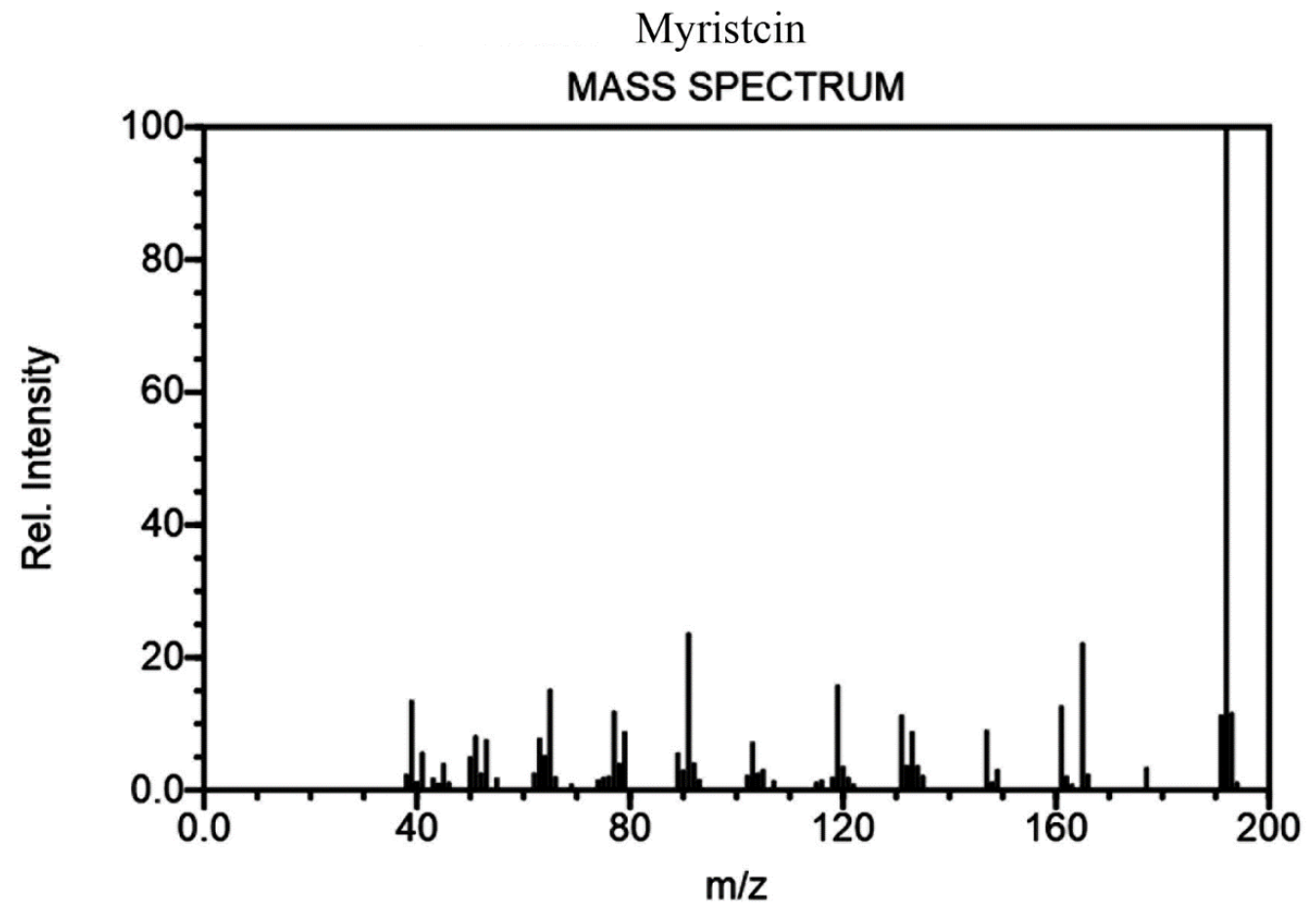

Figure 2: Mass spectrum of Myristcin 
It was found that the essential oil of Astragalus Maximus was a complex mixture of mainly non-terpenoids (90.35\%). Myristcin with 29.4\%, Benzaldehyde, 3-methyl (15.3\%), 1Dodecanol (10.9\%), Acetophenone (10.7\%), 2Pentadecanone, 6,10,14-trimethyl (7.9\%) and Phytol (2.3\%) were the more materials identified as non-terpenoids compounds of the essential oil.
The mass spectrum of the more abundant components of the essential oil of the Astragalus Maximus including Myristcin, Benzaldehyde, 3-methyl, 1-Dodecanol, Acetophenone, 2-Pentadecanone, 6,10,14trimethyl and Phytol were displayed in figures $2,3,4,5$ and 6 , respectively.

Benzaldehyde, 3-methyl-

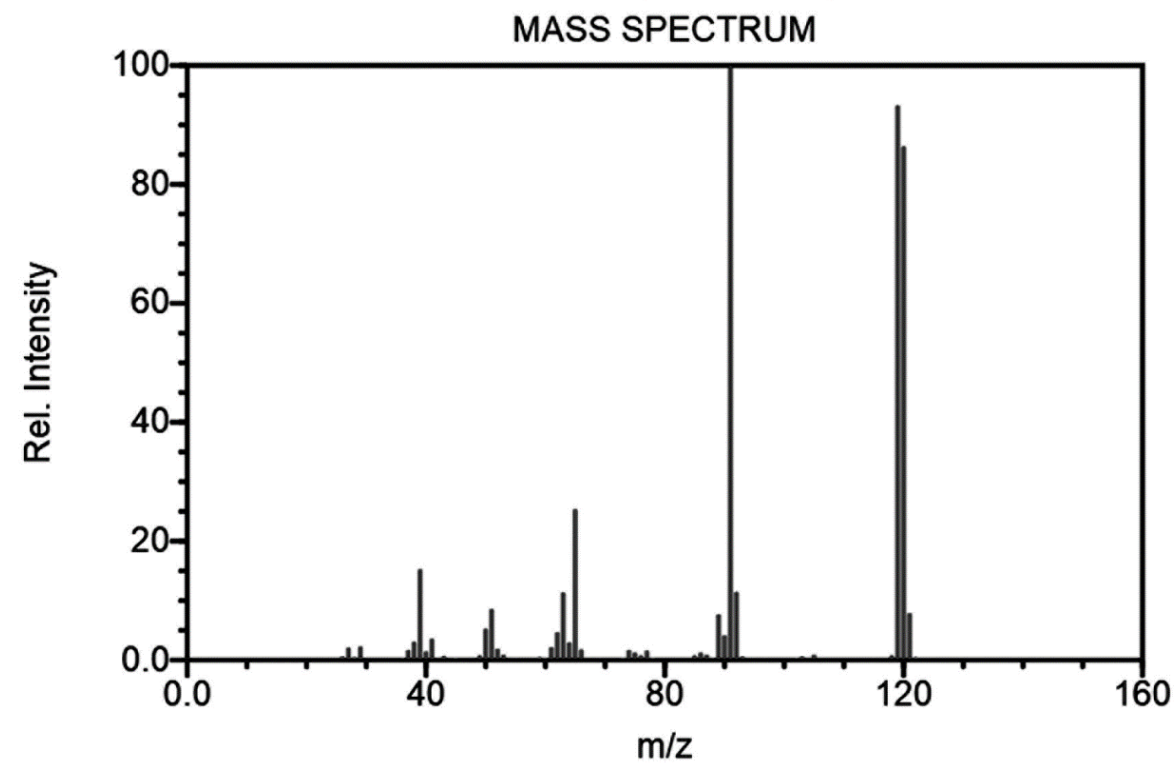

Figure 3: Mass spectrum of Benzaldehyde, 3-methyl

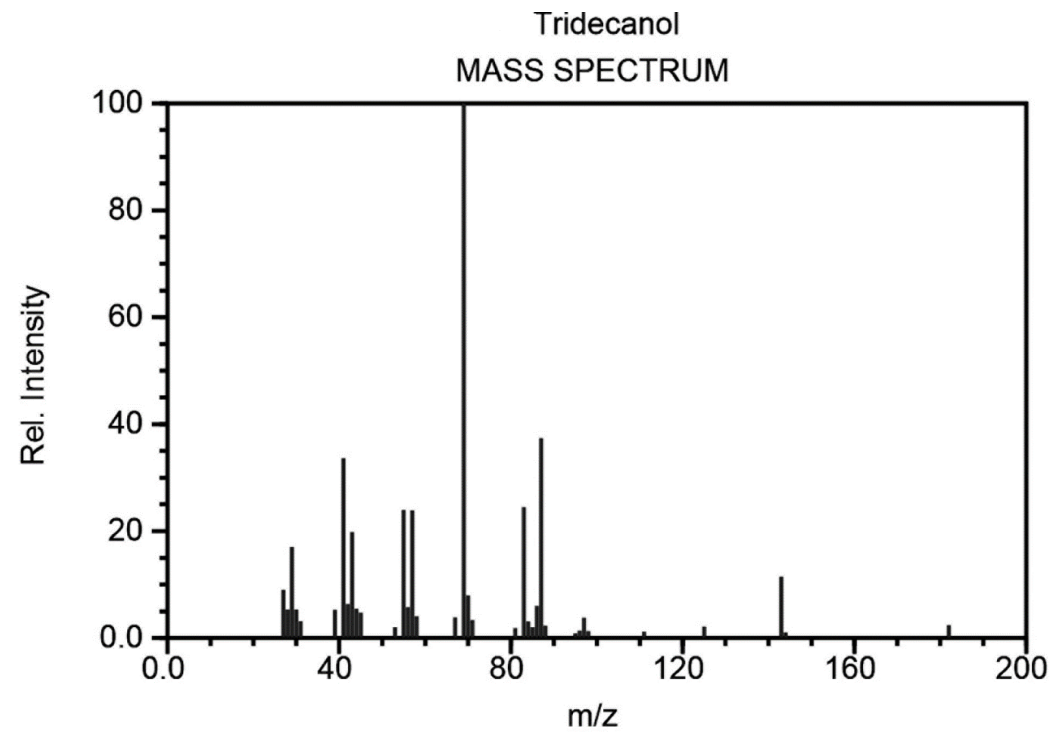

Figure 4: Mass spectrum of Tridecanol 


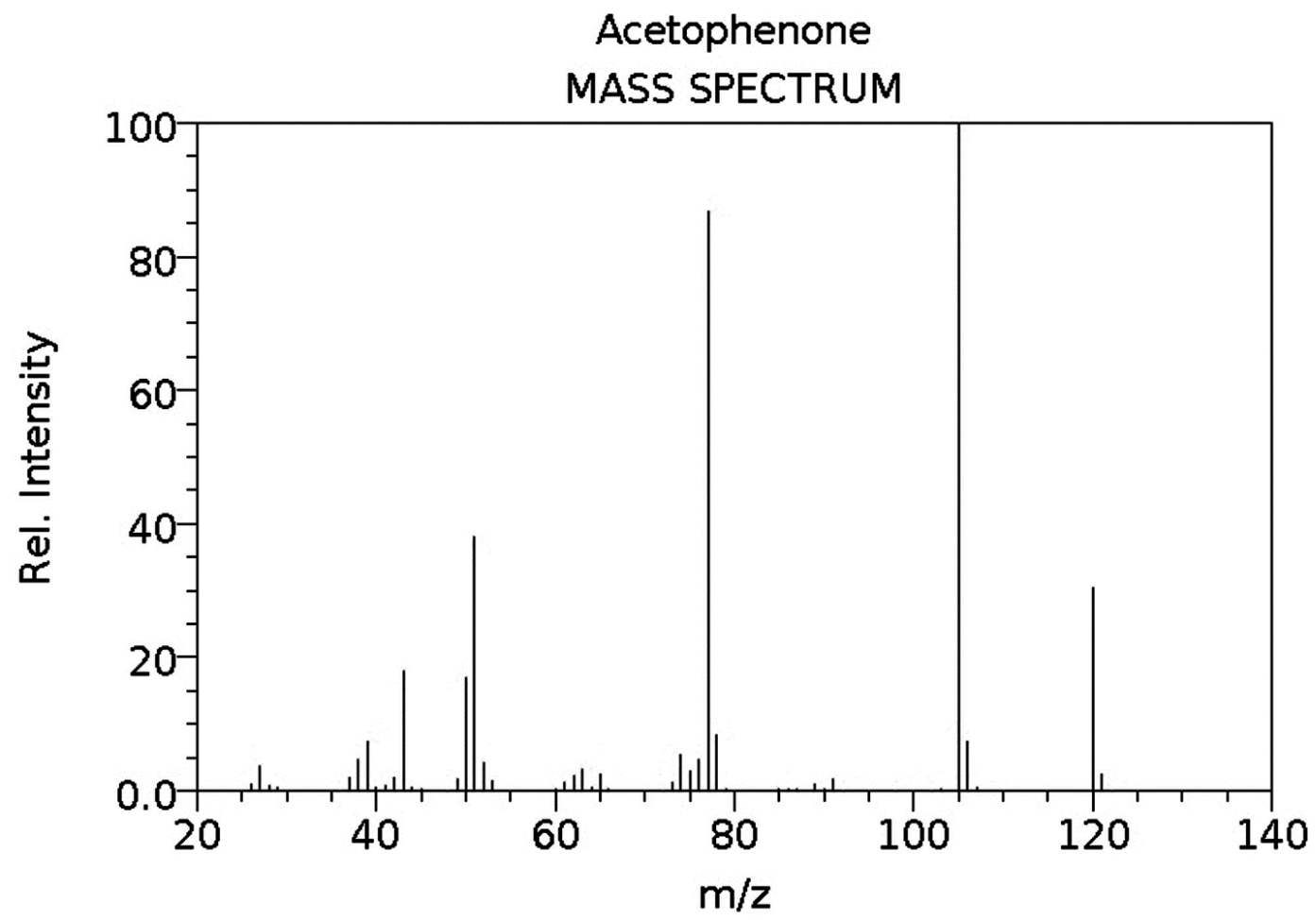

Figure 5: Mass spectrum of Acetophenone

2-Pentadecanone, 6,10,14-trimethyl-

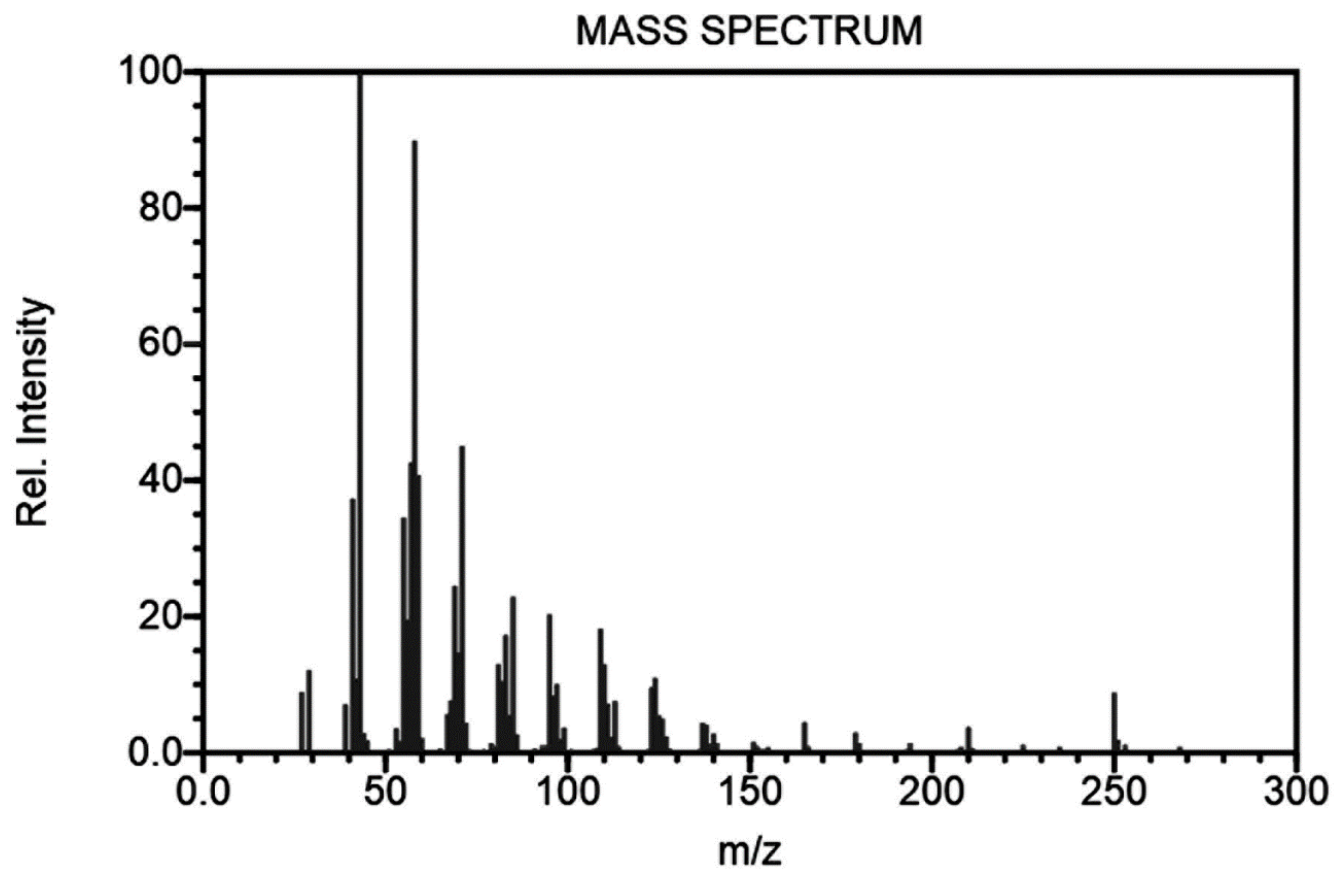

Figure 6: Mass spectrum of 2-Pentadecanone, 6,10,14-trimethyl 
Identification of chemical compositions in water-distilled oils obtained from flowers and leaves of Astragalus schahrudensis, collected from Sabzevar, province Khorasan (Iran), by Akhlaghi et al. showed seventeen compounds from flower oil of the plant including germacrene D (47.6\%) and germacrene B (17.8 $\%)$ as well as fourteen components including $\alpha$ pinene (33.8\%), bornyl acetate (14.2\%), limonene (12.2\%) and $\alpha$-fenchyl acetate (10.0 $\%)$ from leaf oil. The flower oil of Astragalus schahrudensis consisted mainly of sesquiterpenes, while in leaf oil monoterpenes predominated over sesquiterpenes. Also, in Rezaee et al.'s report from the genus Astragalus the hydrodistilled oil from the aerial parts of Astragalus microcephalus Willd were found. The major constituents were hexadecanoic acid (31.9\%), heneicosane (9.1 $\%)$, $\alpha$-cadinene (7.7 \%), tridecanol (6.2 \%) and benzyl benzoate $(6.2 \%)(21,22)$.

\section{Conclusion}

Recently, the usage of the essential oils and various extracts of plants have attracted interest as sources of natural products in aromatherapy and herbal medications. Further studies are necessary to investigate the properties of the essential oil of including antibacterial and antioxidant effects to their potential use as alternative remedies for the treatment of infectious and oxidative diseases as well as the preservation of foods from the toxic effects of bacteria and oxidants. The characterization of Astragalus Maximus has been carried out to identify its components' properties and GC method coupled with MS has been employed to characterize their chemical compositions. This approach is practical and efficient to identify essential oils obtained from different species or varieties for determining components of the essential oil. Overall, essential oil of aerial parts of Astragalus Maximus contains different Non-terpenoid compounds. In summary, the presence of relatively higher amounts of Myristcin, Benzaldehyde, 3-methyl, Tridecanol, Acetophenone, 2-Pentadecanone, 6,10,14trimethyl and Phytol (2.3\%) in the essential oil of the aerial parts Astragalus Maximus was reported for the first time in the present investigation.

\section{Conflict of interest statement}

We declare that we have no conflict of interest.

\section{Acknowledgments}

The data of this article is based on the PhD thesis submitted in Faculty of Pharmacy, Tabriz University of Medical Science (No. 70). Financial support of this study by the Research ViceChancellor of Tabriz University of Medical Sciences is faithfully appreciated. The authors also thank the Drug Applied Research Center of Tabriz University of Medical Sciences for providing technical support for this study.

\section{References}

1. Li R, Xiang C, Ye M, Li H-F, Zhang X, Guo D-A. Qualitative and quantitative analysis of curcuminoids in herbal medicines derived from Curcuma species. Food Chem 2011;126(4):1890-5.

2. Xie $Y$, Jiang Z-H, Zhou H, Cai X, Wong Y-F, Liu Z-Q, et al. Combinative method using HPLC quantitative and qualitative analyses for quality consistency assessment of a herbal medicinal preparation. J Pharm Biomed Anal 2007;43(1):20412.

3. Zhou J-L, Qi L-W, Li P. Herbal medicine analysis by liquid chromatography/time-of-flight mass spectrometry. J Chromatogr A 2009;1216(44):7582-94. 
4. Aleksic V, Knezevic P. Antimicrobial and antioxidative activity of extracts and essential oils of Myrtus communis L. Microbiol Res 2014;169(4):240-54.

5. Boukhatem MN, Kameli A, Saidi F. Essential oil of Algerian rose-scented geranium (Pelargonium graveolens): Chemical composition and antimicrobial activity against food spoilage pathogens. Food Control 2013;34(1):208-13.

6. Đorđević S, Petrović S, Dobrić S, Milenković M, Vučićević D, Žižić S, et al. Antimicrobial, anti-inflammatory, anti-ulcer and antioxidant activities of Carlina acanthifolia root essential oil. J Ethnopharmacol 2007;109(3):458-63.

7. Dastpak A, Kazempour Osaloo S, Maassoumi AA, Amirahmadi A. Phylogenetic analysis of Astragalus sect. Ammodendron (Fabaceae) based on nrDNA ITS and two cpDNAs, psbA-trnH and trnT-trnY sequences. Biochem Syst Ecol 2013;50(0):459-66.

8. Semmar N, Jay M, Farman M, Chemli R. Chemotaxonomic analysis of Astragalus caprinus (Fabaceae) based on the flavonic patterns. Biochem Syst Ecol 2005;33(2):187-200.

9. Zarre S, Rajaiy M, Ebrahimzadeh H, Habibi M, Niknam V. Isozyme variation in some populations of a rare endemic species Astragalus submitis (Fabaceae) in Iran. Biochem Syst Ecol 2004;32(7):675-84.

10. Allam RM, Selim DA, Ghoneim AI, Radwan MM, Nofal SM, Khalifa AE, et al. Hepatoprotective effects of Astragalus kahiricus root extract against ethanol-induced liver apoptosis in rats. Chin J Nat Med 2013;11(4):354-61.

11. Javanmardi F, Kazempour Osaloo S, Maassoumi AA, Nejadsattrai T. Molecular phylogeny of Astragalus section Alopecuroidei (Fabaceae) and its allies based on nrDNA ITS and three cpDNAs, matK, trnT-trnY and trnH-psbA sequences. Biochem Syst Ecol 2012;45(0):171-8.

12. Liston A, Wheeler JA. The phylogenetic position of the genus Astragalus (fabaceae): Evidence from the chloroplast genes rpoC1 and rpoC2. Biochem Syst Ecol 1994;22(4):377-88.

13. Pirani A, Zarre S, Tillich HJ, Podlech D, Niknam V. Spine anatomy and its systematic application in Astragalus sect. Rhacophorus s. L. (Fabaceae) in Iran. Flora - Morphology, Distribution, Functional Ecology of Plants 2006;201(3):240-7.

14. Yesilada E, Bedir E, Çalış I, Takaishi Y, Ohmoto Y. Effects of triterpene saponins from Astragalus species on in vitro cytokine release. J Ethnopharmacol 2005;96(1-2):71-7.

15. Zarre S, Khodaei Z, Karamali Z, Niknam V, Mirmasoumi M. Isoenzyme variation patterns and species concept in Astragalus gossypinus and Astragalus persicus complexes (Fabaceae) in Iran. Biochem Syst Ecol 2007;35(11):757-63.

16. Zhang M, Fritsch PW, Cruz BC. Phylogeny of Caragana (Fabaceae) based on DNA sequence data from rbcL, trnStrnG, and ITS. Mol Phylogenet Evol 2009;50(3):547-59.

17. Li J, Li F, Xu Y, Yang W, Qu L, Xiang Q, et al. Chemical composition and synergistic antioxidant activities of essential oils from Atractylodes macrocephala and Astragalus membranaceus. Natural Product Communications 2013;8(9):1321-4.

18. Teyeb H, Zouari S, Douki W, Najjar MF, Neffati M. Essential oils of leaves, flowers and fruits of Astragalus gombiformis Pomel (Fabaceae). 2010. p. 263-8.

19. Sepahvand R, Delfan B, Ghanbarzadeh S, Rashidipour M, Veiskarami GH, Ghasemian-Yadegari J. Chemical composition, antioxidant activity and antibacterial effect of essential oil of the aerial parts of Salvia sclareoides. Asian Pacific Journal of Tropical Biomedicine 2015;5(1):930-5.

20. Adams R. Identification of Essential oil Components by Gas Chromatography/ Quadrupole Mass Spectroscopy. Carol Stream, IL: Allured Publ Corp; 2004.

21. Rezaee MB, Jaimand K, Karimi M. Chemical constituents of the essential oil from Astragalus microcephalus Willd. J Essent Oil Res 2006 18:84-5.

22. Akhlaghi H. Chemical Composition of the Essential Oil from Aerial Parts of Astragalus schahrudensis Bge. from Northeast of Iran. Journal of Essential Oils Bearing Plants 2009;12(1):59-63. 